\title{
CD44 and its ligand hyaluronan as potential biomarkers in malignant pleural mesothelioma: evidence and perspectives
}

\author{
Lourdes Cortes-Dericks ${ }^{*}$ ib and Ralph Alexander Schmid
}

\begin{abstract}
Malignant pleural mesothelioma (MPM) is a rare and highly drug resistant tumor arising from the mesothelial surfaces of the lung pleura. The standard method to confirm MPM is the tedious, time-consuming cytological examination of cancer biopsy. Biomarkers that are detectable in pleural effusion or patient serum are reasonable options to provide a faster and noninvasive diagnostic approach. As yet, the current biomarkers for MPM lack specificity and sensitivity to discriminate this neoplasm from other lung tumors. CD44, a multifunctional surface receptor has been implicated in tumor progression in different cancers including MPM. The interaction of CD44 with its ligand, hyaluronan (HA) has demonstrated an important role in modulating cell proliferation and invasiveness in MPM. In particular, the high expression levels of these molecules have shown diagnostic relevance in MPM. This review will summarize the biology and diagnostic implication of CD44 and HA as well as the interaction of both molecules in MPM that will demonstrate their potential as biomarkers. Augmentation of the current markers in MPM may lead to an earlier diagnosis and management of this disease.
\end{abstract}

Keywords: CD44, Hyaluronan, Malignant pleural mesothelioma, Biomarker

\section{Background}

MPM is an aggressive, and locally invasive tumor emanating from the mesothelial cells of the pleura mainly due to chronic exposure to asbestos fibers [1-3]. Although it is well accepted that asbestos is the major causative agent of MPM, the number of cases involving persons with less asbestos exposure is also increasing [4]. The diagnosis of MPM is complex because of its composite epithelial/mesenchymal patterns, its phenotypic variability from patient to patient, and its property to mimic other cancers particularly, adenocarcinoma or benign processes [5]. Histologically, MPM is divided into epitheloid, sarcomatoid and biphasic subtypes, which has an impact on diagnosis, treatment and prognosis of the disease. The epitheloid is the most common and least aggressive representing 50-70\% of all MPM cases. The sarcomatoid, a less prevalent subtype is the most aggressive form and by far difficult to manage. The biphasic, a combination of both epitheloid and

\footnotetext{
* Correspondence: cortes-dericks@gmx.de

Department of Clinical Research, Division of General Thoracic Surgery, University Hospital Berne, Berne, Switzerland
}

sarcomatoid comprises $20-35 \%$ of all MPM cases [6, 7]. MPM is highly tolerant to all standard treatments that include the first-line chemotherapy consisting of cisplatin and pemetrexed, surgery and radiation [1]. Response rate to standard chemotherapy is $20-40 \%$ with a median survival time of less than 12 months $[6,8]$. Prognosis remains poor because of the difficulties of early diagnosis, hence, application of biomakers with high sensitivity particularly for the early stage of the disease remains a continuing task $[9,10]$.

The National Cancer Institute defines a biomarker as a biological molecule found in the blood, body fluids or tissues representing a sign of a normal or abnormal process, or of a condition or disease. Biomarkers include proteins (e.g. enzyme or receptor), nucleic acids (e.g. micro RNA), antibodies and peptides and, thus, can be easily obtained noninvasively and serially [11], and neither require biopsy or special imaging for evaluation [12].

One of the established tumor biomarkers is the cluster of differentiation 44 (CD44), an adhesion/homing molecule and the major receptor for HA [13-15]. As a multifunctional cell surface receptor, CD44 has been 
associated in the development of many neoplasms because of its modulating ability in cancer progression such as conveying cell adhesion and cell migration that aids the expansion of tumors [16-18]. CD44 has also been dubbed as a putative cancer stem cell (CSC) in lung cancers and MPM because of its significant influence on disease progression and negative treatment outcome [19-25]. These attributes render CD44 as a biomarker in screening, differential diagnosis and prediction of response to therapy [26]. HA, the most common ligand of CD44 [19] is a glycosaminoglycan (GAG), which is widely distributed within the extracellular matrix. In this compartment, HA regulates different cellular activities such as cell migration, growth and differentiation and cell adhesion [27-30]. High levels of HA in pleural effusions of MPM patients have shown evidence of its diagnostic value in MPM sustaining the idea of being a predictive biomarker in this tumor [31-37]. Herein, we will describe the biology of CD44 and HA, and summarize their diagnostic performance in MPM. It will also discuss the inaccuracy of the conventional biomarkers in pleural fluids/serum for MPM as well as the rationale why CD44 and HA may serve as diagnostic biomarkers that may add to an earlier diagnosis and commencement of appropriate therapies in this disease.

\section{CD44 molecule}

CD44 is a cell surface adhesion molecule involved in cell-cell and cell-matrix interactions $[16,38]$. The interaction of CD44 with its ligand and associated molecules regulate cell adhesiveness, cell motility, matrix degradation, cell proliferation and survival that potentiate its crucial role in carcinogenesis $[17,18]$. CD44, the major receptor for the hyaluronan (previously named hyaluronic acid, HA) is endogeneously expressed at low levels in different types of normal tissues that necessitates activation before binding to HA [39, 40]. Variant isoforms of CD44 specially, CD44 v6-v10 are overexpressed in both human and animal neoplasms indicating its implication in cancer progression, whereas its removal is associated with inhibition of tumor growth [41-44]. Inhibitors such as exemestane, trametinib and statin exert profound antiproliferative effects on mesothelioma growth either by a direct downregulation of CD44 [45] or the suppression of CD44 and its associated signaling pathways $[46,47]$ attesting the critical role of CD44 in modulating tumor growth in MPM.

The CD44 structure on normal cells is different from that on tumor cells because under various physiological and pathological conditions, the local environmental pressure alters splicing and post-translational modifications to produce various types of CD44 molecules with enhanced HA binding that triggers increased tumorigenicity $[13,16$, 48-51]. CD44 can be cleaved at the membrane-proximal region of the ectodomain by MT1-MMP (membrane type 1 matrix metalloproteinase), which is thought to play an essential role in CD44-mediated tumor cell migration alongside with extracellular matrix components [5254]. Although all CD44 isoforms are endowed with HA recognition sites, not all cells bearing CD44 bind the HA ligand constitutively. In addition to HA, CD44 interacts with different ECM proteins such as fibronectin, collagens, growth factors, cytokines, chemokines, matrix metalloproteinases and osteopontin [16].

Twenty exons are involved in the genomic organization of CD44. The first five and the last five exons are constant whereas the ten exons located between these regions are subjected to alternative splicing from which the variable regions emanate (Fig. 1a). The smallest molecule (85$95 \mathrm{kDa}$ ) without the variable region is the standard CD44 (CD44s) (Fig. 1b). As this is found mainly on cells of lymphohematopoietic origin, $\mathrm{CD} 44 \mathrm{~s}$ is also known as hematopoietic CD44 $(\mathrm{CD} 44 \mathrm{H})$. After immunological activation, $\mathrm{T}$ lymphocytes and other leukocytes transiently upregulate CD44 isoforms expressing variant exons designated as CD44v. A CD44 isoform containing the last exon products of the variable region, CD44v8-10 is also known as epithelial CD44 (CD44E) and is preferentially expressed on epithelial cells [50]. CD44v6 (CD44 variant exon 6) is the major CD44 isoform that regulates tumor invasion, progression and metastasis [18, 55] (Fig. 1c). Several MPM cell lines are positive for CD44v9 (variable exon 9) including the CD44v8-10, the former being statistically associated with NF2 (neurofibromatosis type 2), a common feature of MPM [56]. The protein structure of CD44 consists of an N-terminal HAbinding link-homology motif, stem region, transmembrane domain and short C-terminal cytoplasmic region (Fig. 1d). CD44 binds to its major ligand, HA via the $\mathrm{N}$ terminal HA- binding link-homology motif. The Cterminal cytoplasmic region has a major role in eliciting the essential functions of CD44 in the regulation of intracellular signal transduction through binding to different molecules such as the cytoskeleton components, kinases and activators of small Rho GTPases [57, 58].

\section{CD44 ligand, hyaluronan}

Balazs et al. [59] introduced the term "hyaluronan" in 1986 to conform with the international nomenclature of polysaccharides to include the different forms this molecule can take such as the acid form, hyaluronic, and the salt form, sodium hyaluronate. [60]. HA is a non-sulfated, linear GAG consisting of repeating disaccharides of ( $(3,1-4)$-glucoronic acid (GlcUA) and ( $(3,1-$ 3)-N-acetyl glucosamine (GlcNAc). HA is synthesized at the cell plasma membrane by specific hyaluronan synthases (HAS); HAS-1, HAS-2 and HAS-3 and is directly released into the extracellular matrix $[14,30]$. At 


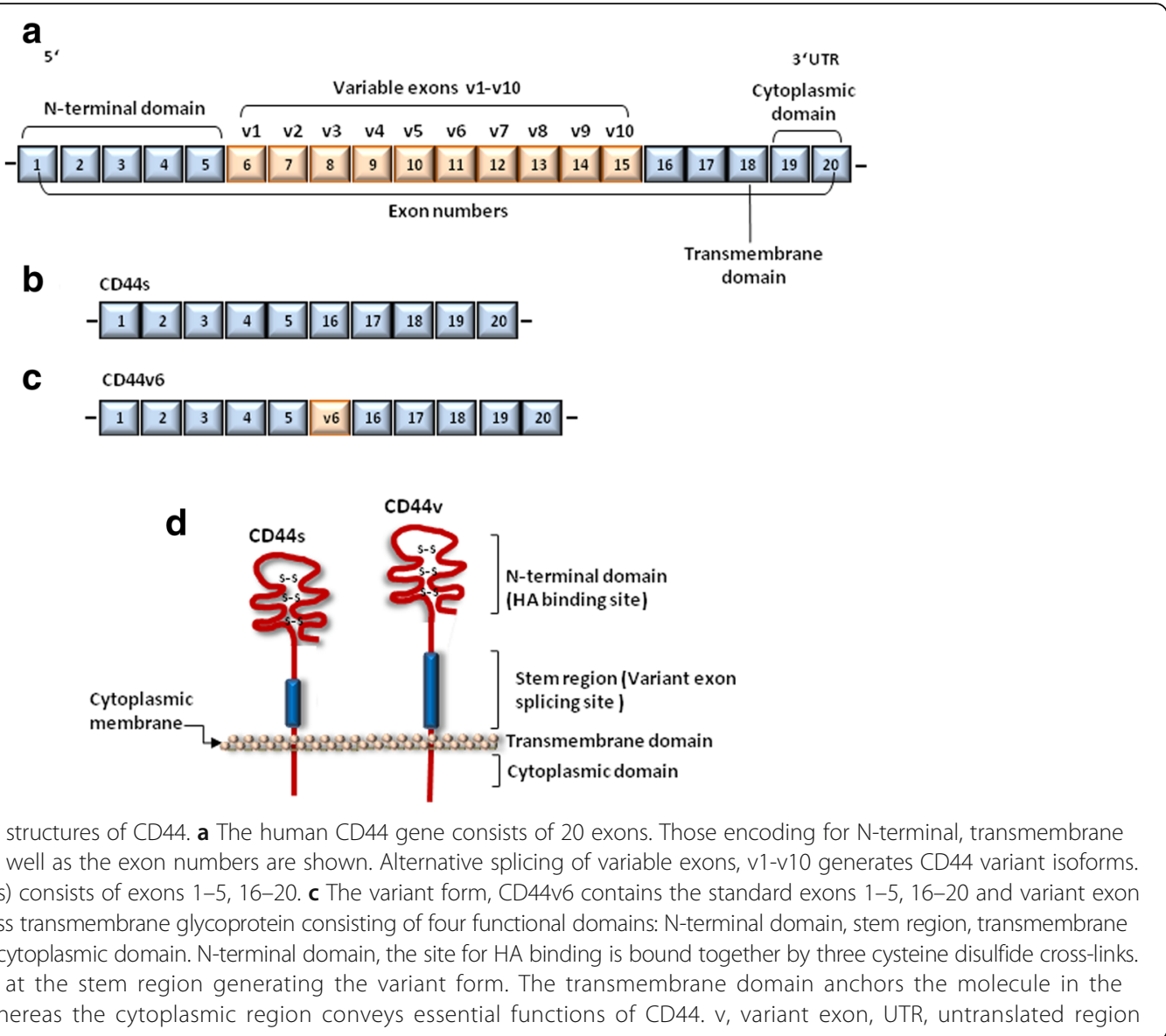

Fig. 1 Genomic and protein structures of CD44. a The human CD44 gene consists of 20 exons. Those encoding for N-terminal, transmembrane and cytoplasmic domains as well as the exon numbers are shown. Alternative splicing of variable exons, v1-v10 generates CD44 variant isoforms. b The standard CD44 (CD44s) consists of exons 1-5, 16-20. c The variant form, CD44v6 contains the standard exons 1-5, 16-20 and variant exon 11 (v6). $\mathbf{d}$ CD44 is a single-pass transmembrane glycoprotein consisting of four functional domains: N-terminal domain, stem region, transmembrane domain and the intracellular cytoplasmic domain. N-terminal domain, the site for HA binding is bound together by three cysteine disulfide cross-links. Alternative splicing occurs at the stem region generating the variant form. The transmembrane domain anchors the molecule in the cytoplasmic membrane, whereas the cytoplasmic region conveys essential functions of CD44. V, variant exon, UTR, untranslated region

the cellular level, HA plays essential roles in modulation of tissue architecture, cell motility, cell proliferation and is a prominent component of the microenvironment in most malignant tumors $[14,42]$. The diverse functions of HA within the extracellular matrix is a result of the different HA-binding receptors such as CD44, RHAMM (receptor for HA-mediated motility), other receptors bearing HAbinding motifs such as the transmembrane protein layilin, HARE (HA receptor for endocytosis), LYVE-1 (lymphatic vessel endocytic receptor), intracellular HA-binding proteins including CD37, RHAMM/IHABP (intracellular HA-binding protein), P-32 and IHABP4 [28, 60].

Upregulated HA production is supposed to produce less dense matrix, hence, providing the cell a suitable platform for increased cell motility and invasion property [61]. Because HA not only provides a cellular support and hydrophilic matrix but also facilitates cell-cell adhesion, cell migration, growth and differentiation, these properties bestow HA as a suitable candidate in modulating pathological processes such as cancer [29, 62]. Elevated levels of HA have been detected in different types of human cancer and its accumulation within the tumor stroma has been associated with poor prognosis and survival in cancer patient [63]. In liver fibrosis, increasing levels of serum
HA have been measured during the progression of the disease [64-66].

In tumors, HA binding to CD44 evokes an interaction of CD44 with signaling receptors such as the epidermal growth factor receptor-2 (ErbB2), epidermal growth factor receptor (EGFR) and transforming growth factor beta receptor type 1 (TGFßR1) that consequently alters the physiological effects of these receptors [67-69]. It can also interact and consequently modify the activity of nonreceptor kinases of the Src family or Ras family GTPases, and with switch molecules such as RhoA, Rac1 and Ras via adaptor proteins that generate intracellular signaling circuits $[14,15,67,68,70,71]$. In such a way, CD44/HA binding modifies the activity of different downstream signaling cascades, in particular, the MAP kinase and PI3/Akt pathways and consequently convey tumor cell proliferation, cell survival, cell motility and invasiveness and chemoresistance [14, 72] (Fig. 2).

\section{CD44/HA interactions in MPM}

CD44 in cancer cells interacts with hyaluronan-rich microenvironments modifying cell signaling pathways that trigger the ability of malignant cells to migrate, to invade basement membranes and to lodge at distant 


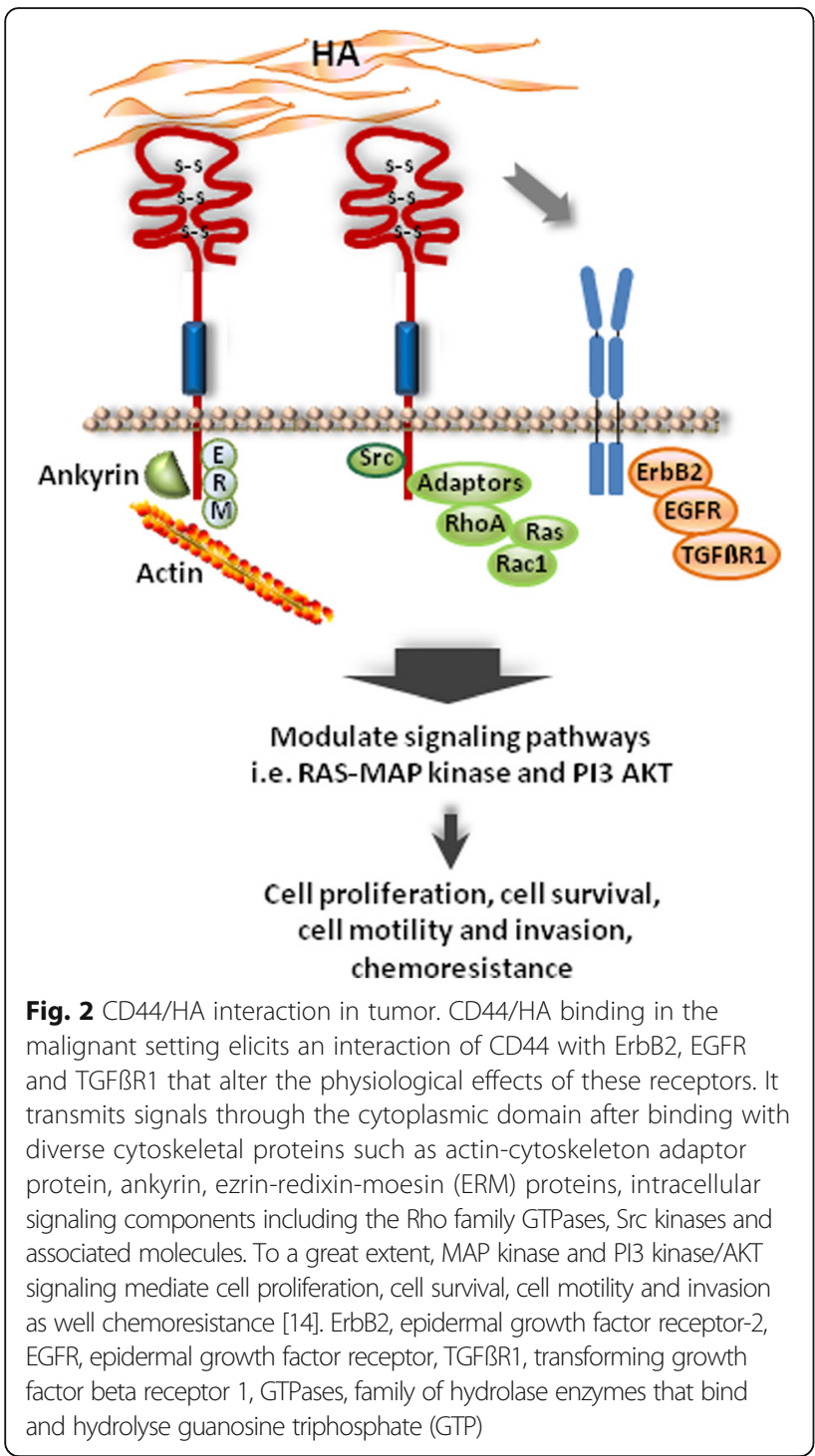

sites of the tumor $[14,70,73]$. That CD44/HA binding mediates several tumor cell-specific activities and progression indicates that $\mathrm{CD} 44 / \mathrm{HA}$ interactions play a pivotal role in cancer development $[67,71]$. In MPM, the presence of HA and its receptor, CD44 have been shown to facilitate neoplastic cell motility and invasion linking CD44/HA interactions in tumor progression.

Li and Heldin [27] provided evidence that the overexpression of hyaluronan synthase 2 (HAS2) in a nonhyaluronan producing MPM cell line, Mero-25, changed the histological type of Mero-25 from less aggressive epitheloid to a more aggressive fibroblastic phenotype. These authors further observed that HAS2-transfected cells demonstrated a two-fold increase in the expression of the HA receptor, CD44 accompanied by increased cell motility, thus, disclosing the critical role of $\mathrm{HA}$ in the dissemination of mesothelioma cells in adjacent nontumor tissues. In a separate study, HA/CD44 interactions in the 2 MPM cell lines ACC-MESO-1 and K921MSO, exhibited a crucial role in driving cell proliferation and invasiveness. These MPM cell lines, which express high quantities of CD44 demonstrated enhanced cell proliferation and upregulated invasion capacity after HA treatments, in vitro. Notably, it was found that silencing of CD44 significantly abrogated the HA-mediated cellular effects in the 2 MPM cell lines indicating the essential role of $\mathrm{CD} 44 / \mathrm{HA}$ binding in modulating migration and proliferation of mesothelioma cells [74].

A comparative analysis between the low molecular weight hyaluronan (LMWHA) and high molecular weight hyaluronan (HMWHA) has been performed to assess their capacity in mediating cell proliferation and migration on 4 MPM cell lines, expressing CD44. This study made evident that the MPM cell line expressing the highest level of CD44 was induced by LMWHA, which resulted to an increased cell proliferation and haptotaxic migration. In this work, CD44 neutralization profoundly reduced LMWHA binding to MMC (malignant mesothelima cells) illustrating that the interaction between $\mathrm{CD} 44$ and HA components transmit regulatory signals conferring locomotion and proliferation of MMC and, thus, show their participation in the expansion of tumor [7].

A mechanistic CD44/HA association in MPM has been observed by Asplund and Heldin [75]. These authors found HA-binding sites on the cell surface of three tumor-derived MPM cell lines, which were absent in normal mesothelial cells. The HA receptors appeared to be related to CD44 because the human CD44 monoclonal antibody, Hermes-1, which prevented the binding of HA to CD44 suppressed the major part of the HA binding mechanism. However, no strict correlation was recorded between the HA binding activity on the tested cells, and the levels of CD44 molecules on their cell surfaces indicating that only a fraction of the HA was bound to the CD44, and that other HA binding proteins may also exist. This study also revealed that the pleural fluids from MPM patients were capable of stimulating HA synthesis in primary mesothelial cultures expressing functionally active HA receptors, CD44.

Osteopontin (OPN), a secreted tumor-associated, noncollagenous phosphoprotein is an extracellular matrix component and a cytokine through binding to its receptors integrin and CD44 [76, 77]. An important role of OPN in MPM has been reported such as the modulation of multidrug resistance via osteopontin-dependent regulation of HA-CD44 interaction. Tajima and coworkers [78] presented evidence that the insertion of OPN gene in stable transfected ACC-MESO-1/OPN cell line upregulated the multidrug resistance through the mechanism of enhanced HA binding. Notably, the inhibition of HACD44 interaction abrogated multidrug resistance in the ACC-MESO-1/OPN sustaining an important role of 
HA-CD44 association in the regulation of drug tolerance and, thus, demonstrate that OPN is essentially implicated in conveying multidrug resistance by enhancing CD44 binding to HA.

\section{Diagnostic relevance of CD44 in MPM}

As in the case of other biomarkers, the utility of CD44 as a diagnostic and/or prognostic marker was originally suggested because of its altered overexpression in human tumor tissues as compared with the nontumor or corresponding normal tissues. An early study of Penno et al. [79] has demonstrated that CD44 can be detected immunohistochemically in MPM tissues illustrating the presence of neoplastic cells. In this project, using a CD44 monoclonal antibody (H4C4), 92\% of the MPM samples were found to contain $50-100 \%$ CD44 relative to the total number of cells. It was further noted that CD44 expression was related to the histological type of MPM, with the highest levels observed in the epitheloid subtype and the least in sarcomatoid. These authors also elucidated that increased CD44 levels modulates the association with HA, a major component of the pleural fluid.

Because MPM is more aggressive than pulmonary adenocarcinoma (ADC), Attanoos and coworkers [80] tested the diagnostic potential of CD44 to discriminate the two neoplasms by immunohistochemistry (IHC) in reactive mesothelium, pleural mesothelioma and pulmonary ADC. A strong immunoreactivity of $\mathrm{CD} 44 \mathrm{H}$ (CD44s) was detected in all 20 biopsies of reactive mesothelium and in $75 \%$ of MPM specimens as compared to only $15 \%$ in pulmonary ADC, thus, proposing the utility of $\mathrm{CD} 44 \mathrm{H}$ as a positive mesothelial marker alongside with established immunohistochemical indicators to differentiate ADC from MPM. CD44 localization in addition to HA by IHC has also been reported to discriminate MPM from ADC [81]. Membranous staining for CD44s was assessed positive in $100 \%$ of mesothelial hyperplasia, $86 \%$ of malignant mesothelioma and $8 \%$ of lung ADCs indicating that $\mathrm{CD} 44 \mathrm{~s}$ is a reliable marker to distinguish MPM from ADC. In yet another study, low CD44 expression was detected in MPM (57.7\%) and in mesothelial hyperplasia (11.5\%) using immunohistochemical analysis. Despite of the low expression of CD44 in the malignant samples, it was suggested that the mere presence of CD44 confirmed its potential as a positive mesothelial marker in the differential diagnosis of pleural neoplastic proliferation [82].

Using CD44, hyaluronan and HASs as putative markers for differentiating MPM from adenocarcinomas (ADCs), Törrönen et al. [83] recently found a surprisingly low CD44 positivity of stromal cells in ADCs as compared to mesotheliomas (MPMs). This report is unanticipated in the sense that, most results have accounted for an increased CD44 levels in MPM in contrast to those in ADCs $[79,80]$.
Porcel and colleagues [84] also compared the diagnostic utility of the concentrations of CD44v6 and CD44s in pleural fluids as biomarkers for distinguishing MPM from nonmesothelioma tumors. The CD44v6/CD44s ratio obtained from the concentration levels between MPM and other pleural malignancies has been proven as a reliable diagnostic tool for the differential diagnosis of malignant pleural effusions such that those with a high probability of being metastatic and, hence, preventing the need of an invasive thoracoscopy. An overview of the diagnostic relevance of CD44 in MPM is shown in Table 1.

\section{Diagnostic value of HA in MPM}

One of the earliest pathological reports on HA was its isolation in 1939 from the pleural fluid of a patient with a malignant tumor of the pleural and peritoneum, which demonstrated that neoplastic cells secrete HA [85]. This was followed by a consensus that the high concentration of HA in the pleural effusions or ascites of MPM patients is a standard finding $[37,86,87]$ or is associated with MPM [83]. Indeed about 70\% of MPM patients exhibit high levels of HA in pleural effusions or serum [88] in which a direct correlation has been found between the upregulated hyaluronan levels in the circulation and tumor damage in HA-producing mesotheliomas [34, 35, 88].

One parameter by which MPM affirms its mesenchymal origin is by the formation of HA, making it as one of the most important criteria in distinguishing between MPM and metastatic ADC [80, 87, 89]. In fact, tumor-secreted $\mathrm{HA}$ in the pleural fluid has been suggested as a means of identifying MPMs [31, 33, 81, 86, 90-93]. In this context, Waxler and coworkers [94] developed a method for isolating HA and other GAGs from tumor tissues and observed that MPMs contained only or almost entirely HA, whereas carcinomas and sarcomas consisted of a mixture of HA and other GAGs. Based on this, these authors concluded HA as the sole or major GAG to confirm a diagnosis of MPM. Another study suggested that increased total GAG aids in the differential diagnosis between MPM and diffuse ADC [95] and is a basic finding in addition to the elevated levels of HA and chondroitin sulfate in MPM [96]. Welker et al. [97] further recommended that the combination of HA and cytology may even improve the diagnosis of MPM.

An earlier report has found that HA values of $>0.25 \mu \mathrm{g} / \mathrm{ml}$ in pleural effusions indicates the presence of MPM [86]. Using a higher cut-off level of $100 \mu \mathrm{g} / \mathrm{ml}$ for HA, Atagi et al. [92] as well as Petterson and colleagues [33] reported that such a high concentration of HA in the pleural fluid combined with a low concentration of carcinoembryonic antigen (CEA) aid in the differential diagnosis for MPM. As a single marker, HA values of $>100 \mu \mathrm{g} / \mathrm{ml}$ has been recommended as a diagnostic indicator for MPM [31]. 
Table 1 Diagnostic relevance of CD44 in MPM

\begin{tabular}{|c|c|c|}
\hline Function & Method/specimen & Reference \\
\hline High CD44 level indicates presence of neoplastic cells & IHC/MPM tissues & Penno et al. 1995 [79] \\
\hline High CD44 level differentiates MPM from ADC & IHC/reactive mesothelium, MPM, ADC samples & Attanoos et al. 1997 [80] \\
\hline CD44/HA localization discriminates MPM from ADC & IHC/paraffin-embedded serous fluids & Afify et al. 2005 [81] \\
\hline $\begin{array}{l}\text { CD44v6/CD44s ratio aids in differential diagnosis } \\
\text { between MPM and non-MPM tumors }\end{array}$ & ELISA/Pleural fluids & Porcel et al. 2011 [84] \\
\hline $\begin{array}{l}\text { Low CD44 level aids in differential diagnosis of } \\
\text { pleural neoplastic differentiation }\end{array}$ & $\begin{array}{l}\text { IHC/epitheloid MPM and reactive mesothelial } \\
\text { hyperplasia tissues }\end{array}$ & Ali et al. 2013 [82] \\
\hline $\begin{array}{l}\text { Low CD44 positivity and high HA staining may } \\
\text { differentiate MPM from ADC }\end{array}$ & IHC/MPM tissues & Törronen et al. 2016 [83] \\
\hline
\end{tabular}

High serum levels of HA in MPM patients have been measured in MPM patients in later and progressive stages [34] denoting $\mathrm{HA}$ as a marker of a progressive disease [35, 88]. An accumulation of high intracellular $\mathrm{HA}$, a feature that is not reported in ADC, could distinguish MPM from ADC according to Afify and coworkers [81]. Their study revealed that all MPMs and $93 \%$ of the benign mesothelial cells were positive for intracytoplasmic HA as compared with a 100\% negativity in ADCs. In contrast to this report, the group of Chiu [87] claimed that HA is neither the sole nor the predominant GAG in most MPMs. These authors found that quantitatively, MPMs exhibited statistically higher amounts of HA than primary lung ADCs but were not statistically different from soft tissue sarcomas or primary ovarian serous neoplasms. Hence, they suggested that high levels of HA support the diagnosis of MPM when the alternative diagnosis is primary ADC of the lung. Intriguingly, high levels of HA in pleural fluid have been proposed not to be specific for MPM as it can also occur in other malignant or benign diseases and a low level does not exclude MPM [98].

Another aspect of importance is that the pleural fluids from MPM patients exhibited profound HA-stimulatory activity as compared with the nonmesothelioma fluids, thus, demonstrating that HA-binding capacity may serve as an additional marker in combination with other diagnostic tools to delineate between MPM and normal mesothelial cells [99]. Table 2 shows an overview of the diagnostic value of HA in MPM.

\section{CD44, a putative cancer stem cell marker in MPM}

MPM is a notoriously chemoresistant neoplasm which led to the identification of a cancer stem cell subpopulation with the presumption that these cells are crucial candidates for conferring drug tolerance. The CSC model proposes that these cells have the capacity for self-renewal, re-initiation of tumor growth and innate resistance to chemotherapy $[23,25,26,100]$. CD 44, principally, $\mathrm{CD} 44 \mathrm{v}$ isoforms are CSC markers that play essential roles in the execution of the fundamental features of CSCs $[19,26,101,102]$. Hence, CD44 has been proposed to be used for the isolation and enrichment of CSCs in lung cancers including MPM $[22,24,26,100,103]$.

That MPM contains a subpopulation of CSCs has been reported by using putative CSC markers in addition to CD44. For instance, the side population (SP) associated with CD105 [104], SP, CD9, CD24 and CD26 [105] were used in MPM cells lines and mesothelioma-derived primary cells to identify the presence of a CSC subpopulation. Using established CSC-associated genes, our group detected the presence of polycomb ring finger oncogene, $(\mathrm{Bmi}-1)^{+}$, urokinase plasminogen activator receptor ( $\mathrm{uPAR})^{+}$and ATP-binding cassette subfamily G, member $2\left(\mathrm{ABCG}^{+}\right)^{+}$cells in 3 MPM cell lines, which elicited resistance to cisplatin and pemetrexed, indicating the presence of a drug- resistant CSC subpopulation [106]. In the H28, H2052 and Meso4 MPM cell lines, we noted a marked increase in CD44 transcript levels within the putative $\mathrm{CSC} \mathrm{ALDH}^{+} \mathrm{CD} 44^{+}$-sorted cells after cisplatin treatments, revealing the involvement of CD44 in ensuing drug resistance [22]. Using an activated cell sorting (FACS)-based assay, we also measured high percentages of CD44 ${ }^{+}$cells in the following MPM cell lines: $\mathrm{H} 28-48.5 \%$; H2052 - 57.6\% and Meso4 - 50.2\% relative to the entire cell population sustaining the presence of a putative CSC subpopulation (Cortes-Dericks et al., unpublished report).

There is reasonable consensus that CD44 as a putative CSC marker could identify a drug-resistant subpopulation [22, 24-26] - a possible clinical attribute of MPM, which may be considered as a new diagnostic parameter of the disease.

\section{"Conventional" biomarkers in pleural effusion and serum for MPM}

Pleural fluid cytology is considered a reliable diagnostic tool for MPM only in experienced centres. For this reason, most of the patients undergo invasive procedures such as core-needle biopsy or video-assisted thoracoscopy to facilitate histological examination - the gold standard for MPM diagnosis [5, 107-111]. Thus, the search for a noninvasive diagnostic procedure that may confirm or exclude the diagnosis of MPM is of major clinical interest [108]. 
Table 2 Diagnostic value of HA in MPM

\begin{tabular}{|c|c|c|}
\hline Function & Method/specimen & Reference \\
\hline HA is associated with malignant tumor of the pleura & Enzymatic analysis/pleural fluid & Meyer and Chaffee. 1940 [85] \\
\hline HA proposed as a diagnostic tool & Electrophoresis/Pleural fluids & Boersma et al. 1975 [91] \\
\hline HA as a major GAG confirms MPM diagnosis & Electrophoresis/MPM and other tumor tissues & Waxler et al. 1979 [94] \\
\hline High HA is a clinical finding in MPM & GAG-degrading enzyme assay/pleural tissues & Arai et al. 1979 [36] \\
\hline $\begin{array}{l}\text { Increased total GAG aids in differential diagnosis } \\
\text { between diffuse MPM and ADC }\end{array}$ & IHC/MPM tissues & Kawai et al. 1985 [95] \\
\hline HA indicates diffuse MPM & Colorimetric assay/pleural fluids & Matzel and Schubert. 1979 [93] \\
\hline $\begin{array}{l}\text { HA aids in differential diagnosis between MPM and } \\
\text { primary ADC }\end{array}$ & Electrophoresis/MPM and other tumor tissues & Chiu et al. 1984 [87] \\
\hline Increased HA level is associated with tumor damage & IHC/pleural effusions & $\begin{array}{l}\text { Thylen et al. } 1999 \text { [88] } \\
\text { Dahl et al. } 1989 \text { [35] }\end{array}$ \\
\hline HA is an indicator for MPM & HPLC/pleural and peritoneal effusions & Roboz et al. 1985 [86] \\
\hline Increased serum HA indicates progressive MPM & Radiometric assay/patient serum & $\begin{array}{l}\text { Frebourg et al. } 1987 \text { [34] } \\
\text { Dahl et al. } 1984 \\
\text { Thylen et al. } 1994\end{array}$ \\
\hline HA and chondroitin sulfate are basic features of MPM & IHC/tumor tissues and pleural fluids & Nakano et al. 1986 [96] \\
\hline Positive HA staining highly predictive of MPM & HA-binding probe/MPM and ADC tissues & Azumi et al. 1992 [90] \\
\hline Presence of HA distinguishes MPM from ADC & IHC, HPLC/pleural effusion and tumor tissues & $\begin{array}{l}\text { Klominek et al. } 1989 \text { [89] } \\
\text { Attanoos et al. } 1997[80]\end{array}$ \\
\hline High HA with CEA aid in differential diagnosis of MPM & Radiometric assay/Pleural fluids and patient serum & $\begin{array}{l}\text { Atagi et al. } 1997 \text { [92] } \\
\text { Pettersson et al. } 1988 \text { [33] }\end{array}$ \\
\hline $\begin{array}{l}\text { Increased HA-binding in pleural effusion cells serves } \\
\text { as additional diagnostic marker }\end{array}$ & {$[3 \mathrm{H}]$ hyaluronate binding assay/primary cell cultures } & Teder et al. 1996 [99] \\
\hline High intracellular HA delineates MPM from ADC & $\mathrm{HC} /$ serous fluids & Afify et al. 2005 [81] \\
\hline Increased HA level is not specific for MPM diagnosis & ELISA assay/Pleural effusions and serum & Hillerdal et al. 1991 [98] \\
\hline $\begin{array}{l}\text { Combination of HA and cytology may improve diagnosis } \\
\text { of MPM }\end{array}$ & Immunoassay and IHC/pleural effusions & Welker et al. 2007 [97] \\
\hline $\begin{array}{l}\text { HA }>100000 \mathrm{ng} / \mathrm{ml} \text { recommended as diagnostic indicator } \\
\text { for MPM }\end{array}$ & ELISA assay pleural fluids of MPM and other tumors & Fujimoto et al. 2013 [31] \\
\hline High HA is associated with MPM & IHC/MPM tissues & Töronnen et al. 2016 [83] \\
\hline
\end{tabular}

MPM malignant pleural mesothelioma, ADC adenocarcinoma, HA hyaluronic acid, GAG glycosaminoglycan, IHC immunohistochemistry, ELISA enzyme-linked immunosorbent assay, HPLC high pressure liquid chromatography

Biomarkers that can be analysed in serum, pleural effusions or blood may solve the tedious diagnostic procedure. Those that can be measured in pleural effusions have the advantage of being readily applicable for analysis at the onset of the first clinical symptoms for most patients [112] and may allow the early detection of the disease.

The "conventional" biomarkers in pleural fluid and/or serum for MPM still do not warrant an accurate diagnosis. OPN, soluble mesothelin, formerly known as soluble mesothelin-related peptide (SMRP) [113, 114], and megakaryocyte potentiating factor (MPF) also known as N-ECR/ mesothelin $[112,115]$ are supposed to be the most promising but with some limitations due to lack of specificity and sensitivity [4, 116-118]. Mesothelin and MPF, both soluble glycoproteins $[119,120]$ have sufficient specificity but have a sub-optimal sensitivity for detection of MPM, being negative in both the sarcomatoid and almost half of the epitheloid subtype, particularly in the early stages $[116,121]$.
OPN lacks specificity for the diagnosis of MPM but may be valuable in disease monitoring $[116,122]$.

The glycoprotein fibulin-3 is thought to have a high diagnostic accuracy for MPM being able to distinguish between asbestos-exposed non-MPM patients and early stages of MPM [123]. However, Creany and associates [124] found that although fibulin-3 is highly expressed in MPM, its diagnostic power as a plasma or pleural effusion biomarker is less than that of mesothelin. HA as a single marker is not sufficient to discriminate MPM from benign effusion [83]. Although increased levels of HA has shown high diagnostic potential in MPM, its sensitivity and specificity is low in detecting MPM $[4,125]$. Other tumor markers in serum and pleural fluid have been reported to be of diagnostic importance such as cytokeratin19 fragment (CYFRA 21-1), carcinoembryonic antigen (CEA), cancer antigen 15-3 (CA 15-3), cancer antigen 15-9 (CA 15-9) and tissue polypeptide antigen (TPA); 
however, these markers are not sensitive or specific enough and, thus, cannot be applied clinically [4].

At this time, mesothelin remains the most clinically useful and the only Food Drug and Administration (FDA)-approved, single-best blood-based biomarker in the diagnosis of MPM. It has also been proposed to be a standard control in testing the sensitivity of a potential biomarker [117, 122, 124, 126-129].

\section{"Best practice" biomarker, mesothelin combined with other potential markers}

Owing to the restrictions in sensitivity and specificity of single biomarkers, the use of combinatorial biomarkers have been evaluated to discriminate between asymptomatic asbestos-exposed subjects and early-stage MPM patients. As mesothelin is considered the most useful biomarker in MPM [117, 124, 126], a number of studies have been undertaken to enhance its diagnostic competence.

The combination of CA125 and serum mesothelin were evaluated in patients with MPM, healthy asbestos-exposed individuals, patients with asbestos-related lung disease and with benign pleural effusions to augment the sensitivity of mesothelin as a single marker. The results from this study did not show improvement of the combined CA125 and mesothelin relative to the sensitivity of mesothelin alone [130]. Notably, combined mesothelin and CEA enhanced the diagnostic accuracy in distinguishing MPM from non-small cell lung cancer (NSCLC) [131]. Muley and coworkers [132] also obtained data attesting that the dual application of mesothelin and CEA significantly increased the differential diagnosis between MPM and other lung cancers, and also between MPM and benign asbestos disease. Hence, these authors endorsed the combination of both markers for the diagnosis as well as for differential diagnosis.

The combination of serum mesothelin and HA has not improved the diagnostic performance over mesothelin alone [129]. Adversely, the team of Creany [125] furnished information that the combination of the "best practice" biomarker, mesothelin and HA have a higher diagnostic capability than using effusion mesothelin as a single marker. A comparative study between the diagnostic accuracy of fibulin-3 and mesothelin in the plasma and pleural effusions of MPM patients indicated that mesothelin generates a better diagnostic efficiency compared with fibulin-3 for MPM, whereas fibulin-3 renders superior prognostic values relative to mesothelin [124].

The combined diagnostic power of OPN and mesothelin did not provide a stronger diagnostic capacity than that of mesothelin alone [133]. Even the combination of OPN, MPF and mesothelin did not furnish a superior effect than mesothelin alone. Intriguingly, a recent study reported that the combination of serum OPN and mesothelin have a diagnostic potential in differentiating MPM from benign asbestos-related diseases and asbestos-exposed subjects [134].

At the clinical setting, studies on the combination of biomarkers have not been diagnostically satisfactory over individual markers but is encouraging as sensitive, soluble markers are emerging and being tested $[9,116,118]$.

\section{CD44 and HA as potential biomarkers in MPM}

The review of literature presented herein strongly implies that CD44 and its ligand HA are potentially useful biomarkers in MPM. The increased expression levels of both molecules in MPM tissues and pleural fluids as compared with the normal mesothelial cells strongly reinforces their implication in the development of MPM as well as their diagnostic performance. A tight CD44/ HA interaction also asserts that both molecules convey biological actions in a concerted manner so that both may be considered as tandem biomarkers. CD44/HA as dual markers have been suggested in the differential diagnosis between MPM and ADC. As these markers still do not provide diagnostic accuracy, the inclusion of both CD44 and HA in a panel of biomarkers has been recommended [83]. As mentioned earlier, the combination of mesothelin/HA has shown an improved diagnostic accuracy. In this context, the incorporation of CD44 in the combined mesothelin/HA may even generate a reliable diagnosis, which warrants an extensive validation.

The proposed criteria for future biomarkers for MPM namely; their measurability in biological samples using minimally invasive tests, to differentiate MPM from benign pleural disease, applicability for all pathological subtypes and correlation with the extent of malignancy [4, 135], may be well achieved after appropriate in vitro and clinical evaluation. HA, CD44s and CD44 isoforms can readily be detected by an ELISA (enzyme-linked immunosorbent assay) assay in pleural effusion, serum, plasma and other biological fluids, which can be procured in a noninvasive procedure. Several MPM putative biomarkers have been generally based on the expression levels of molecules via mRNA microarray studies [118, 136-138], which can also be used for measuring the expression levels of CD44 and its isoforms including HA. Apart from the potential of $\mathrm{CD} 44$ and HA to provide an accurate diagnosis, the practicability of evaluating the expression levels also warrants faster results and less exhausting method for the patient.

\section{Conclusion}

The general recommendations from the different pathologists worldwide for the diagnosis of MPM still advocate the use of an immunohistological examination of a conventionally stained tissue samples as the gold standard for MPM diagnosis $[5,118,139,140]$. It still takes several months between the first signs of the disease and a definite diagnosis of MPM is achieved. Rationally, there should 
be a marker or a combination of markers that will offer an accurate diagnosis of MPM based on pleural effusion analysis that may be incorporated with routine immunohistochemistry or electron microscopy of cell pellets [112]. There is ample evidence that one marker alone is not sufficient to detect, differentiate and specifically diagnose MPM. Because of the tight association of HA and CD44, it stands to reason that combining the two markers or their inclusion in a panel of markers may serve as adjuvant diagnostic tool to efficiently aid the early and most likely specific diagnosis of MPM.

\begin{abstract}
Abbreviations
ABCG2: ATP-binding cassette subfamily G, member 2; ADC: Adenocarcinoma; Bmi-1: Polycomb ring finger oncogene; CA 125: Cancer antigen 125; CA

15-9: Cancer antigen 15-9; CA15-3: Cancer antigen 15-3; CEA: Carcinoembryonic antigen; CSC: Cancer stem cell; CYFRA 21-1: Cytokeratin-19 fragment; ECR/ mesothelin: Precursor protein that can lead to a $31 \mathrm{kDa}$ MPF or N-ECR/mesothelin-protein; EGFR: Epidermal growth factor receptor; ErbB2: Epidermal growth factor receptor-2; GAG: Glycosaminoglycan; GlcNAc: N-acetyl glucosamine; GlcUA: Glucoronic acid; GTPases: Guanosine triphosphatases; HA: Hyaluronan, hyaluronic acid; HARE: HA receptor for endocytosis; HAS: Hyaluronan synthases; HMWHA: High molecular weight hyaluronan; IHABP: Intracellular hyaluronanbinding protein; IHAPB4: Intracellular hyaluronan-binding protein 4; LMWHA: Low molecular weight hyaluronan; LWE-1: Lymphatic vessel endocytic receptor; MAP kinase: Mitogen-activated protein kinase; MMC: Malignant mesothelioma cells; MPF: Megakaryocyte potentiating factor; MPM: Malignant pleural mesothelioma; MT1-MMP: Membrane type 1 metalloproteinase; OPN: Osteopontin; PI3/ AKT: Phosphoinositide 3-kinase/protein kinase B; RHAMM: Receptor for HA-mediated motility; SMRP: Soluble mesothelin-related peptide; SP: Side population; TGFBR1: Transforming growth factor beta receptor type 1; TPA: Tissue polypeptide antigen; UPAR: Urokinase plasminogen activator receptor
\end{abstract}

\section{Acknowledgements}

Not applicable.

\section{Funding}

Bernische Krebsliga.

\section{Authors'contribution}

LCD conceived and wrote the manuscript. RAS ensured that important topics are appropriately discussed and gave the final approval of the manuscript. Both authors read and approved the final manuscript.

\section{Availability of data and materials}

The authors' unpublished data are available upon request.

\section{Competing of interest}

The authors declare that they have no conflict of interest.

\section{Consent for publication}

Not applicable.

Ethics approval and consent to participate Not applicable.

\section{Publisher's Note}

Springer Nature remains neutral with regard to jurisdictional claims in published maps and institutional affiliations.

Received: 15 February 2017 Accepted: 6 April 2017

Published online: 12 April 2017

\section{References}

1. Sekido Y. Molecular pathogenesis of malignant mesothelioma. Carcinogenesis. 2013;34:1413-9.

2. Mott FE. Mesothelioma: A Review. Ochsner J. 2012;12:70-9.
3. Fennell DA, Gaudino G, O'Byrne K, Mutti L, van Meerbeeck J. Advances in the systemic therapy of malignant pleural mesothelioma. Nat Clin Pract Oncol. 2008;5:136-47.

4. Tomasetti M, Santarelli L. Biomarkers for early detection of malignant mesothelioma: diagnostic and therapeutic application. Cancers. 2010;2:523-48.

5. Ascoli V. Pathologic diagnosis of malignant mesothelioma: chronological prospect and advent of recommendations and guidelines. Ann Delllstituto Super Sanità. 2015;51:52-9.

6. Porpodis K, Zarogoulidis P, Boutsikou E, Papaioannou A, Machairiotis N, Tsakiridis K, et al. Malignant pleural mesothelioma: current and future perspectives. J Thorac Dis. 2013;5 Suppl 4:S397-406.

7. Nasreen N, Mohammed KA, Hardwick J, Van Horn RD, Sanders K, Kathuria H, et al. Low molecular weight hyaluronan induces malignant mesothelioma cell (MMC) proliferation and haptotaxis: role of $C D 44$ receptor in $M M C$ proliferation and haptotaxis. Oncol Res. 2002;13:71-8.

8. Remon J, Reguart N, Corral J, Lianes P. Malignant pleural mesothelioma: new hope in the horizon with novel therapeutic strategies. Cancer Treat Rev. 2015;41:27-34.

9. Panou V, Vyberg M, Weinreich UM, Meristoudis C, Falkmer UG, Røe OD. The established and future biomarkers of malignant pleural mesothelioma. Cancer Treat Rev. 2015;41:486-95.

10. Creaney J, Robinson BWS. Serum and pleural fluid biomarkers for mesothelioma. Curr Opin Pulm Med. 2009;15:366-70.

11. Biomarkers Definitions Working Group. Biomarkers and surrogate endpoints: preferred definitions and conceptual framework. Clin Pharmacol Ther. 2001; 69:89-95.

12. Henry NL, Hayes DF. Cancer biomarkers. Mol Oncol. 2012;6:140-6.

13. Misra S, Heldin P, Hascall VC, Karamanos NK, Skandalis SS, Markwald RR, et al. Hyaluronan-CD44 interactions as potential targets for cancer therapy. FEBS J. 2011:278:1429-43.

14. Toole BP. Hyaluronan-CD44 Interactions in Cancer: Paradoxes and Possibilities. Clin Cancer Res. 2009:15:7462-8.

15. Toole BP, Slomiany MG. Hyaluronan, CD44 and Emmprin: Partners in cancer cell chemoresistance. Drug Resist Updat. 2008;11:110-21.

16. Goodison S, Urquidi V, Tarin D. CD44 cell adhesion molecules. Mol Pathol. 1999;52:189-96

17. Jothy S. CD44 and its partners in metastasis. Clin Exp Metastasis. 2003;20: 195-201.

18. Marhaba R, Zöller M. CD44 in cancer progression: adhesion, migration and growth regulation. J Mol Histol. 2004;35:211-31.

19. Thapa R, Wilson GD, Thapa R, Wilson GD. The Importance of CD44 as a Stem Cell Biomarker and Therapeutic Target in Cancer, The Importance of CD44 as a Stem Cell Biomarker and Therapeutic Target in Cancer. Stem Cells Int. 2016;2016:e2087204.

20. Wang J, Li Z, White J, Zhang L. Lung cancer stem cells and implications for future therapeutics. Cell Biochem Biophys. 2014;69:389-98.

21. Roudi R, Madjd Z, Korourian A, Mehrazma M, Molanae S, Sabet MN, et al. Clinical significance of putative cancer stem cell marker CD44 in different histological subtypes of lung cancer. Cancer Biomark Sect Dis Markers. 2014; 14:457-67.

22. Cortes-Dericks L, Froment L, Boesch R, Schmid RA, Karoubi G. Cisplatin-resistant cells in malignant pleural mesothelioma cell lines show ALDH (high) CD44 (+) phenotype and sphere-forming capacity. BMC Cancer. 2014;14:304.

23. Alamgeer M, Peacock CD, Matsui W, Ganju V, Watkins DN. Cancer stem cells in lung cancer: Evidence and controversies. Respirol Carlton Vic. 2013;18:757-64.

24. Leung EL-H, Fiscus RR, Tung JW, Tin VP-C, Cheng LC, Sihoe AD-L, et al. Nonsmall cell lung cancer cells expressing CD44 are enriched for stem cell-like properties. PLoS One. 2010;5:e14062.

25. Eramo A, Haas TL, De Maria R. Lung cancer stem cells: tools and targets to fight lung cancer. Oncogene. 2010;29:4625-35.

26. Yan $Y$, Zuo $X$, Wei D. Concise review: emerging role of CD44 in cancer stem cells: a promising biomarker and therapeutic target. Stem Cells Transl Med. 2015;4:1033-43.

27. Li Y, Heldin P. Hyaluronan production increases the malignant properties of mesothelioma cells. Br J Cancer. 2001;85:600-7.

28. Knudson W. The role of CD44 as a cell surface hyaluronan receptor during tumor invasion of connective tissue. Front Biosci J Virtual Libr. 1998;3:d604-615.

29. Laurent TC, Laurent UB, Fraser JR. Functions of hyaluronan. Ann Rheum Dis. 1995;54:429-32.

30. Laurent TC, Laurent UB, Fraser JR. The structure and function of hyaluronan: An overview. Immunol Cell Biol. 1996;74:A1-7. 
31. Fujimoto N, Gemba K, Asano M, Fuchimoto Y, Wada S, Ono K, et al. Hyaluronic acid in the pleural fluid of patients with malignant pleural mesothelioma. Respir Investig. 2013;51:92-7.

32. Martensson G, Thylen A, Lindquist U, Hjerpe A. The sensitivity of hyaluronan analysis of pleural fluid from patients with malignant mesothelioma and a comparison of different methods. Cancer. 1994;73:1406-10.

33. Pettersson T, Fröseth B, Riska H, Klockars M. Concentration of hyaluronic acid in pleural fluid as a diagnostic aid for malignant mesothelioma. Chest. 1988;94:1037-9.

34. Frebourg T, Lerebours $G$, Delpech B, Benhamou D, Bertrand P, Maingonnat $C$, et al. Serum hyaluronate in malignant pleural mesothelioma. Cancer. 1987;59:2104-7.

35. Dahl IM, Solheim OP, Erikstein B, Müller E. A longitudinal study of the hyaluronan level in the serum of patients with malignant mesothelioma under treatment. Hyaluronan as an indicator of progressive disease. Cancer. 1989;64:68-73.

36. Arai $H$, Kang KY, Sato H, Satoh K, Nagai H, Motomiya M, et al. Significance of the quantification and demonstration of hyaluronic acid in tissue specimens for the diagnosis of pleural mesothelioma. Am Rev Respir Dis. 1979;120:529-32.

37. Arai H. A study on acid glycosaminoglycans in pleural diseases. Sci Rep Res Inst Tohoku Univ Med. 1979;26:46-70.

38. Naor D, Nedvetzki S, Golan I, Melnik L, Faitelson Y. CD44 in cancer. Crit Rev Clin Lab Sci. 2002;39:527-79.

39. Mackay CR, Terpe HJ, Stauder R, Marston WL, Stark H, Günthert U. Expression and modulation of CD44 variant isoforms in humans. J Cell Biol. $1994 ; 124: 71-82$

40. Sneath RJ, Mangham DC. The normal structure and function of CD44 and its role in neoplasia. Mol Pathol. 1998:51:191-200.

41. Karousou E, Misra S, Ghatak S, Dobra K, Götte M, Vigetti D, et al. Roles and targeting of the HAS/hyaluronan/CD44 molecular system in cancer. Matrix Biol. 2017:59:3-22.

42. Misra S, Hascall VC, Markwald RR, Ghatak S. Interactions between Hyaluronan and Its Receptors (CD44, RHAMM) Regulate the Activities of Inflammation and Cancer. Front Immunol. 2015;6. doi:10.3389/fimmu.2015.00201

43. Rudzki Z, Jothy S. CD44 and the adhesion of neoplastic cells. Mol Pathol. 1997:50:57-71.

44. Tran TA, Kallakury BV, Sheehan CE, Ross JS. Expression of CD44 standard form and variant isoforms in non-small cell lung carcinomas. Hum Pathol. 1997:28:809-14

45. Cho H, Matsumoto S, Fujita Y, Kuroda A, Menju T, Sonobe M, et al. Trametinib plus 4-methylumbelliferone exhibits antitumor effects by ERK blockade and CD44 downregulation and affects PD-1 and PD-L1 in malignant pleural mesothelioma. J Thorac Oncol. 2017;12:477-90.

46. Nuvoli B, Germoni S, Morosetti C, Santoro R, Cortese G, Masi S, et al. Exemestane blocks mesothelioma growth through downregulation of CAMP, pCREB and CD44 implicating new treatment option in patients affected by this disease. Mol Cancer. 2014;13:69.

47. Tanaka K, Osada H, Murakami-Tonami Y, Horio Y, Hida T, Sekido Y. Statin suppresses Hippo pathway-inactivated malignant mesothelioma cells and blocks the YAP/CD44 growth stimulatory axis. Cancer Lett. 2017;385:215-24.

48. Bourguignon LY, Zhu H, Shao L, Chen YW. CD44 interaction with tiam1 promotes Rac1 signaling and hyaluronic acid-mediated breast tumor cell migration. J Biol Chem. 2000;275:1829-38.

49. Bourguignon LY, Zhu D, Zhu H. CD44 isoform-cytoskeleton interaction in oncogenic signaling and tumor progression. Front Biosci. 1998;3:d637-649.

50. Naor D, Sionov RV, Ish-Shalom D. CD44: structure, function, and association with the malignant process. Adv Cancer Res. 1997;71:241-319.

51. Bourguignon LYW, Singleton PA, Zhu H, Zhou B. Hyaluronan promotes signaling interaction between CD44 and the transforming growth factor beta receptor I in metastatic breast tumor cells. J Biol Chem. 2002;277:39703-12

52. Okamoto I, Kawano Y, Tsuiki H, Sasaki J, Nakao M, Matsumoto M, et al. CD44 cleavage induced by a membrane-associated metalloprotease plays a critical role in tumor cell migration. Oncogene. 1999;18:1435-46.

53. Okamoto I, Tsuiki H, Kenyon LC, Godwin AK, Emlet DR, Holgado-Madruga M, et al. Proteolytic cleavage of the CD44 adhesion molecule in multiple human tumors. Am J Pathol. 2002;160:441-7.

54. Sugahara KN, Hirata T, Hayasaka H, Stern R, Murai T, Miyasaka M. Tumor cells enhance their own CD44 cleavage and motility by generating hyaluronan fragments. J Biol Chem. 2006;281:5861-8.

55. Fox SB, Fawcett J, Jackson DG, Collins I, Gatter KC, Harris AL, et al. Normal human tissues, in addition to some tumors, express multiple different CD44 isoforms. Cancer Res. 1994:54:4539-46.
56. Chew SH, Okazaki Y, Akatsuka S, Wang S, Jiang L, Ohara Y, et al. Rheostatic CD44 isoform expression and its association with oxidative stress in human malignant mesothelioma. Free Radic Biol Med. 2017;106:91-9.

57. Dzwonek J, Wilczynski GM. CD44: molecular interactions, signaling and functions in the nervous system. Front Cell Neurosci. 2015;9:175.

58. Thorne RF, Legg JW, Isacke CM. The role of the CD44 transmembrane and cytoplasmic domains in co-ordinating adhesive and signalling events. J Cell Sci. 2004;117(Pt 3):373-80.

59. Balazs EA, Laurent TC, Jeanloz RW. Nomenclature of hyaluronic acid. Biochem J. 1986;235:903.

60. Necas J, Bartosikova L, Brauner P, Kolar J. Hyaluronic acid (hyaluronan): a review. Veterinari Medicina. 2008:8:397-411

61. Hill A, McFarlane S, Johnston PG, Waugh DJJ. The emerging role of CD44 in regulating skeletal micrometastasis. Cancer Lett. 2006;237:1-9.

62. Laurent TC, Fraser JR. Hyaluronan. FASEB J. 1992:6:2397-404.

63. Chanmee T, Ontong P, Kimata K, Itano N. Key roles of hyaluronan and its CD44 receptor in the stemness and survival of cancer stem cells. Front Oncol. 2015;5:180

64. Geramizadeh B, Janfeshan K, Saberfiroozi M. Serum hyaluronic acid as a noninvasive marker of hepatic fibrosis in chronic hepatitis B. Saudi J Gastroenterol. 2008;14:174-7.

65. Halfon P, Bourlière M, Pénaranda G, Deydier R, Renou C, Botta-Fridlund D, et al. Accuracy of hyaluronic acid level for predicting liver fibrosis stages in patients with hepatitis C virus. Comp Hepatol. 2005;4:6.

66. Wong VS, Hughes V, Trull A, Wight DG, Petrik J, Alexander GJ. Serum hyaluronic acid is a useful marker of liver fibrosis in chronic hepatitis $C$ virus infection. J Viral Hepat. 1998;5:187-92.

67. Bourguignon LYW. Hyaluronan-mediated CD44 activation of RhoGTPase signaling and cytoskeleton function promotes tumor progression. Semin Cancer Biol. 2008;18:251-9.

68. Toole BP. Hyaluronan: from extracellular glue to pericellular cue. Nat Rev Cancer. 2004:4:528-39.

69. Jiang D, Liang J, Noble PW. Hyaluronan in tissue injury and repair. Annu Rev Cell Dev Biol. 2007;23:435-61.

70. Ponta $H$, Sherman L, Herrlich PA. CD44: from adhesion molecules to signalling regulators. Nat Rev Mol Cell Biol. 2003;4:33-45.

71. Turley EA, Noble PW, Bourguignon LYW. Signaling properties of hyaluronan receptors. J Biol Chem. 2002:277:4589-92.

72. Bourguignon LYW. Hyaluronan-CD44 interaction promotes microRNA signaling and RhoGTPase activation leading to tumor progression. Small GTPases. 2012;3:53-9.

73. Orian-Rousseau V. CD44, a therapeutic target for metastasising tumours. Eur J Cancer. 2010;46:1271-7.

74. Hanagiri T, Shinohara S, Takenaka M, Shigematsu Y, Yasuda M, Shimokawa H, et al. Effects of hyaluronic acid and CD44 interaction on the proliferation and invasiveness of malignant pleural mesothelioma. Tumour Biol. 2012;33:2135-41.

75. Asplund T, Heldin P. Hyaluronan receptors Are expressed on human malignant mesothelioma cells but not on normal mesothelial cells. Cancer Res. 1994:54:4516-23.

76. Cappia S, Righi L, Mirabelli D, Ceppi P, Bacillo E, Ardissone F, et al. Prognostic role of osteopontin expression in malignant pleural mesothelioma. Am J Clin Pathol. 2008;130:58-64

77. Denhardt DT, Noda M, O'Regan AW, Pavlin D, Berman JS. Osteopontin as a means to cope with environmental insults: regulation of inflammation, tissue remodeling, and cell survival. J Clin Invest. 2001;107:1055-61.

78. Tajima K, Ohashi R, Sekido Y, Hida T, Nara T, Hashimoto M, et al. Osteopontin-mediated enhanced hyaluronan binding induces multidrug resistance in mesothelioma cells. Oncogene. 2010;29:1941-51.

79. Penno MB, Askin FB, Ma H, Carbone M, Vargas MP, Pass HI. High CD44 expression on human mesotheliomas mediates association with hyaluronan. Cancer J Sci Am. 1995;1:196-203.

80. Attanoos RL, Webb R, Gibbs AR. CD44H expression in reactive mesothelium, pleural mesothelioma and pulmonary adenocarcinoma. Histopathology. 1997:30:260-3.

81. Afify AM, Stern R, Michael CW. Differentiation of mesothelioma from adenocarcinoma in serous effusions: the role of hyaluronic acid and CD44 localization. Diagn Cytopathol. 2005;32:145-50.

82. Alì G, Borrelli N, Riccardo G, Proietti A, Pelliccioni S, Niccoli C, et al. Differentia expression of extracellular matrix constituents and cell adhesion molecules between malignant pleural mesothelioma and mesothelial hyperplasia. J Thorac Oncol. 2013;8:1389-95. 
83. Törrönen K, Soini Y, Pääkkö P, Parkkinen J, Sironen R, Rilla K. Mesotheliomas show higher hyaluronan positivity around tumor cells than metastatic pulmonary adenocarcinomas. Histol Histopathol. 2016;31:1113-22.

84. Porcel JM, Esquerda A, Rodriguez-Panadero F, Martínez-Iribarren A, Bielsa S. The use of pleural fluid sCD44v6/std ratio for distinguishing mesothelioma from other pleural malignancies. J Thorac Oncol. 2011;6:190-4.

85. Meyer K, Chaffee E. Hyaluronic acid in the pleural fluid associated with a malignant tumor involving the pleura and peritoneum. J Biol Chem. 1940; 133:83-91.

86. Roboz J, Greaves J, Silides D, Chahinian AP, Holland JF. Hyaluronic acid content of effusions as a diagnostic Aid for malignant mesothelioma. Cancer Res. 1985;45:1850-4.

87. Chiu B, Churg A, Tengblad A, Pearce R, McCaughey WTE. Analysis of hyaluronic acid in the diagnosis of malignant mesothelioma. Cancer. 1984; 54:2195-9.

88. Thylén A, Wallin J, Martensson G. Hyaluronan in serum as an indicator of progressive disease in hyaluronan-producing malignant mesothelioma. Cancer. 1999;86:2000-5.

89. Klominek J, Robért K-H, Hjerpe A, Wickström B, Gahrton G. Serumdependent growth patterns of Two, newly established human mesothelioma cell lines. Cancer Res. 1989;49:6118-22.

90. Azumi N, Underhill CB, Kagan E, Sheibani K. A novel biotinylated probe specific for hyaluronate. Its diagnostic value in diffuse malignant mesothelioma. Am J Surg Pathol. 1992;16:116-21.

91. Boersma A, Degand P, Biserte G, Havez R. Report on the study of hyaluronic acid in the diagnosis of pleural mesotheliomas: study of 100 hyaluronic acid rich effusions. Biomedicine. 1975;22:428-32.

92. Atagi S, Ogawara M, Kawahara M, Sakatani M, Furuse K, Ueda E, et al. Utility of hyaluronic acid in pleural fluid for differential diagnosis of pleural effusions: likelihood ratios for malignant mesothelioma. Jpn J Clin Oncol. 1997;27:293-7.

93. Matzel W, Schubert G. Hyaluronic acid in pleural fluids: an additional parameter for clinical diagnosis on diffuse mesotheliomas (author's transl). Arch Geschwulstforsch. 1979;49:146-54.

94. Waxler B, Eisenstein $\mathrm{R}$, Battifora $\mathrm{H}$. Electrophoresis of tissue glycosaminoglycans as an aid in the diagnosis of mesotheliomas. Cancer. 1979:44:221-7

95. Kawai T, Suzuki M, Shinmei M, Maenaka Y, Kageyama K. Glycosaminoglycans in malignant diffuse mesothelioma. Cancer. 1985;56:567-74.

96. Nakano T, Fujii J, Tamura S, Amuro Y, Nabeshima K, Horai T, et al. Glycosaminoglycan in malignant pleural mesothelioma. Cancer. 1986;57:106-10.

97. Welker L, Müller M, Holz O, Vollmer E, Magnussen H, Jörres RA. Cytological diagnosis of malignant mesothelioma-improvement by additional analysis of hyaluronic acid in pleural effusions. Virchows Arch. 2007;450:455-61.

98. Hillerdal G, Lindqvist U, Engström-Laurent A. Hyaluronan in pleural effusions and in serum. Cancer. 1991;67:2410-4.

99. Teder P, Versnel MA, Heldin P. Stimulatory effects of pleural fluids from mesothelioma patients on CD44 expression, hyaluronan production and cell proliferation in primary cultures of normal mesothelial and transformed cells. Int J Cancer. 1996;67:393-8.

100. Hardavella G, George R, Sethi T. Lung cancer stem cells-characteristics, phenotype. Transl Lung Cancer Res. 2016;5:272-9.

101. Zöller M. CD44: can a cancer-initiating cell profit from an abundantly expressed molecule? Nat Rev Cancer. 2011;11:254-67.

102. Williams K, Motiani K, Giridhar PV, Kasper S. CD44 integrates signaling in normal stem cell, cancer stem cell and (pre) metastatic niches. Exp Biol Med. 2013;238:324-38.

103. Wang P, Gao Q, Suo Z, Munthe E, Solberg S, Ma L, et al. Identification and characterization of cells with cancer stem cell properties in human primary lung cancer cell lines. PLoS One. 2013;8:e57020.

104. Frei C, Opitz I, Soltermann A, Fischer B, Moura U, Rehrauer H, et al. Pleural mesothelioma side populations have a precursor phenotype. Carcinogenesis. 2011;32:1324-32.

105. Ghani FI, Yamazaki H, Iwata S, Okamoto T, Aoe K, Okabe K, et al. Identification of cancer stem cell markers in human malignant mesothelioma cells. Biochem Biophys Res Commun. 2011;404:735-42.

106. Cortes-Dericks L, Carboni GL, Schmid RA, Karoubi G. Putative cancer stem cells in malignant pleural mesothelioma show resistance to cisplatin and pemetrexed. Int J Oncol. 2010;37:437-44.

107. Zhang W, Wu X, Wu L, Zhang W, Zhao X. Advances in the diagnosis, treatment and prognosis of malignant pleural mesothelioma. Ann Transl Med. 2015;3:182. doi:10.3978/j.issn.2305-5839.2015.07.03.
108. van der Bij S, Schaake E, Koffijberg H, Burgers JA, de Mol BAJM, Moons KGM Markers for the non-invasive diagnosis of mesothelioma: a systematic review. Br J Cancer. 2011;104:1325-33.

109. Renshaw AA, Dean BR, Antman KH, Sugarbaker DJ, Cibas ES. The role of cytologic evaluation of pleural fluid in the diagnosis of malignant mesothelioma. Chest. 1997;111:106-9.

110. Fletcher SV, Clark RJ. The Portsmouth thoracoscopy experience, an evaluation of service by retrospective case note analysis. Respir Med. 2007;101:1021-5.

111. Fassina A, Fedeli U, Corradin M, Da Frè M, Fabbris L. Accuracy and reproducibility of pleural effusion cytology. Leg Med. 2008;10:20-5.

112. Mundt F, Nilsonne G, Arslan S, Csürös K, Hillerdal G, Yildirim H, et al. Hyaluronan and $\mathrm{N}$-ERC/mesothelin as Key biomarkers in a specific Two-step model to predict pleural malignant mesothelioma. PLoS ONE. 2013;8: e72030. doi:10.1371/journal.pone.0072030.

113. Creaney J, Dick IM, Robinson BWS. Discovery of new biomarkers for malignant mesothelioma. Curr Pulmonol Rep. 2015;4:15-21.

114. Robinson BWS, Creaney J, Lake R, Nowak A, Musk AW, de Klerk N, et al. Mesothelin-family proteins and diagnosis of mesothelioma. Lancet Lond Engl. 2003;362:1612-6.

115. Shiomi K, Hagiwara Y, Sonoue K, Segawa T, Miyashita K, Maeda M, et al. Sensitive and specific New enzyme-linked immunosorbent assay for N-ERC/ mesothelin increases its potential as a useful serum tumor marker for mesothelioma. Clin Cancer Res. 2008;14:1431-7.

116. Pantazopoulos I, Boura P, Xanthos T, Syrigos K. Effectiveness of mesothelin family proteins and osteopontin for malignant mesothelioma. Eur Respir J. 2013:41:706-15

117. Creaney J, Yeoman D, Demelker Y, Segal A, Musk AW, Skates SJ, et al. Comparison of osteopontin, megakaryocyte potentiating factor, and mesothelin proteins as markers in the serum of patients with malignant mesothelioma. J Thorac Oncol. 2008;3:851-7.

118. Greillier L, Baas P, Welch JJ, Hasan B, Passioukov A. Biomarkers for malignant pleural mesothelioma: current status. Mol Diagn Ther. 2008;12:375-90.

119. Lee YCG. Hunting for a pleural fluid test for mesothelioma: is soluble mesothelin the answer? Thorax. 2007;62:561-2.

120. Kojima T, Oh-eda M, Hattori K, Taniguchi Y, Tamura M, Ochi N, et al. Molecular cloning and expression of megakaryocyte potentiating factor CDNA. J Biol Chem. 1995;270:21984-90.

121. Grigoriu BD, Grigoriu C, Chahine B, Gey T, Scherpereel A. Clinical utility of diagnostic markers for malignant pleural mesothelioma. Monaldi Arch Chest Dis. 2009:71:31-8.

122. Scherpereel A, Lee YCG. Biomarkers for mesothelioma. Curr Opin Pulm Med. 2007;13:339-443.

123. Pass HI, Levin SM, Harbut MR, Melamed J, Chiriboga L, Donington J, et al. Fibulin-3 as a blood and effusion biomarker for pleural mesothelioma. N Engl J Med. 2012;367:1417-27.

124. Creaney J, Dick IM, Meniawy TM, Leong SL, Leon JS, Demelker Y, et al. Comparison of fibulin-3 and mesothelin as markers in malignant mesothelioma. Thorax. 2014;69:895-902.

125. Creaney J, Dick IM, Segal A, Musk AW, Robinson BWS. Pleural effusion hyaluronic acid as a prognostic marker in pleural malignant mesothelioma. Lung Cancer. 2013;82:491-8.

126. Creaney J, Robinson BWS. Malignant mesothelioma biomarkers - from discovery to use in clinical practise for diagnosis, monitoring, screening and treatment. Chest. 2016; pii: S0012-3692(16)62593-X .DOI:10.1016/j.chest.2016. 12.004

127. Canessa PA, Franceschini MC, Ferro P, Battolla E, Dessanti P, Manta C, et al. Evaluation of soluble mesothelin-related peptide as a diagnostic marker of malignant pleural mesothelioma effusions: its contribution to cytology. Cancer Invest. 2013;31:43-50.

128. Hollevoet K, Reitsma JB, Creaney J, Grigoriu BD, Robinson BW, Scherpereel A, et al. Serum mesothelin for diagnosing malignant pleural mesothelioma: an individual patient data meta-analysis. J Clin Oncol. 2012;30:1541-9.

129. Grigoriu B, Chahine B, Zerimech F, Grégoire M, Balduyck M, Copin M-C, et al. Serum mesothelin has a higher diagnostic utility than hyaluronic acid in malignant mesothelioma. Clin Biochem. 2009;42:1046-50.

130. Creaney J, van Bruggen I, Hof M, Segal A, Musk AW, de Klerk N, et al. Combined CA125 and mesothelin levels for the diagnosis of malignant mesothelioma. Chest. 2007:132:1239-46.

131. van den Heuvel MM, Korse CM, Bonfrer JMG, Baas P. Non-invasive diagnosis of pleural malignancies: the role of tumour markers. Lung Cancer. 2008:59:350-4. 
132. Muley T, Dienemann H, Herth FJF, Thomas M, Meister M, Schneider J. Combination of mesothelin and CEA significantly improves the differentiation between malignant pleural mesothelioma, benign asbestos disease, and lung cancer. J Thorac Oncol. 2013;8:947-51.

133. Grigoriu B-D, Scherpereel A, Devos P, Chahine B, Letourneux M, Lebailly P, et al. Utility of osteopontin and serum mesothelin in malignant pleural mesothelioma diagnosis and prognosis assessment. Clin Cancer Res. 2007;13:2928-35.

134. Bayram M, Dongel I, Akbaş A, Benli I, Akkoyunlu ME, Bakan ND. Serum Biomarkers in Patients with Mesothelioma and Pleural Plaques and Healthy Subjects Exposed to Naturally Occurring Asbestos. Lung. 2014;192:197-203.

135. Ray M, Kindler HL. Malignant pleural mesothelioma: an update on biomarkers and treatment. Chest. 2009;136:888-96

136. Pass HI, Liu Z, Wali A, Bueno R, Land S, Lott D, et al. Gene expression profiles predict survival and progression of pleural mesothelioma. Clin Cancer Res. 2004;10:849-59.

137. Holloway AJ, Diyagama DS, Opeskin K, Creaney J, Robinson BWS, Lake RA, et al. A molecular diagnostic test for distinguishing lung adenocarcinoma from malignant mesothelioma using cells collected from pleural effusions. Clin Cancer Res. 2006;12:5129-35.

138. Gordon GJ. Transcriptional profiling of mesothelioma using microarrays. Lung Cancer. 2005;49 Suppl 1:S99-103.

139. Panadero FR. Diagnosis and Treatment of Malignant Pleural Mesothelioma. Arch Bronconeumol Engl Ed. 2015;51:177-84.

140. Stahel RA, Weder W, Lievens Y, Felip E. On behalf of the ESMO Guidelines Working Group. Malignant pleural mesothelioma: ESMO Clinical Practice Guidelines for diagnosis, treatment and follow-up. Ann Oncol. 2010 21(Supplement 5):v126-8.

\section{Submit your next manuscript to BioMed Central and we will help you at every step:}

- We accept pre-submission inquiries

- Our selector tool helps you to find the most relevant journal

- We provide round the clock customer support

- Convenient online submission

- Thorough peer review

- Inclusion in PubMed and all major indexing services

- Maximum visibility for your research

Submit your manuscript at www.biomedcentral.com/submit
Biomed Central 